\title{
Foreshocks, Aftershocks, and Earthquake Probabilities: Accounting for the Landers Earthquake
}

\author{
by Lucile M. Jones
}

\begin{abstract}
The equation to determine the probability that an earthquake occurring near a major fault will be a foreshock to a mainshock on that fault is modified to include the case of aftershocks to a previous earthquake occurring near the fault. The addition of aftershocks to the background seismicity makes its less probable that an earthquake will be a foreshock, because nonforeshocks have become more common. As the aftershocks decay with time, the probability that an earthquake will be a foreshock increases. However, fault interactions between the first mainshock and the major fault can increase the long-term probability of a characteristic earthquake on that fault, which will, in turn, increase the probability that an event is a foreshock, compensating for the decrease caused by the aftershocks.
\end{abstract}

\section{Introduction}

Earthquakes cluster in time and space. Hence, once an earthquake has occurred, more earthquakes become more likely. Parameterization of the temporal behavior of earthquake clusters (foreshock and aftershock sequences) has allowed calculation of probabilities of future earthquake activity (Jones, 1985; Reasenberg and Jones, 1989; Agnew and Jones, 1991) even though foreshocks and aftershocks are in no way distinguished from other earthquakes. Although the calculated probabilities of potentially damaging earthquakes $(M \geqq 5$ ) have exceeded $50 \%$ for 3 days only during the aftershock sequences of major earthquakes (e.g., Loma Prieta and Landers), smaller earthquakes can cause the probability to rise several orders of magnitude above the background level. The state of California has used these probabilities as the basis of seven advisories to the public since 1985 . In all of the advisories, the probabilities were small (usually given as a "few percent"). In only one case has an earthquake occurred close to the stated window (an $M$ 5.9 event after 4 days when the window was a few percent chance of an $M 6$ in 3 days).

Agnew and Jones (1991) derived the probability of a characteristic earthquake on a major fault after a smaller earthquake occurs near that fault. They showed that the probability that a small earthquake will be followed by the characteristic earthquake depends upon three quantities - the long-term probability of the characteristic earthquake, the rate at which foreshocks precede the mainshocks, and the rate of background seismicity near the fault. In a region of high background seismicity, an earthquake is more likely to be one of the common background earthquakes and not a foreshock, while in a quiet region, background seismicity is rare and an event is more likely to be a foreshock. This involves the assumption that the rate at which foreshocks precede mainshocks is independent of the rate of background seismicity. Agnew and Jones (1991) applied this methodology to the San Andreas fault system in California and determined probabilities that earthquakes would be foreshocks to large plate-boundary earthquakes as a function of time, location, and magnitude.

The 1992 Landers earthquake sequence brought an application of and a challenge to this method. The 1992 sequence included three large events, the 23 April Joshua Tree ( $M$ 6.1) preshock, the 28 June Landers ( $M$ 7.3) mainshock, and the 28 June Big Bear ( $M$ 6.4) aftershock (Fig. 1). The Joshua Tree earthquake was located $9 \mathrm{~km}$ from the Coachella Valley segment of the southern San Andreas fault, and by the methodology of Agnew and Jones (1991) (who showed that all well-recorded foreshocks in California have occurred within $10 \mathrm{~km}$ of their mainshock), had a probability of $21 \%$ of being a foreshock to a San Andreas mainshock within the next 3 days. On this basis, the state of California issued an advisory warning of the potential of a damaging earthquake on the San Andreas within 3 days. Such an event, of course, did not occur.

Two months later, a major earthquake did occur, not on the San Andreas fault but instead on faults of the eastern California shear zone (Fig. 1). However, the block motions in the Landers earthquake changed the stresses on the southern San Andreas fault so as to make failure more likely (Stein et al., 1992; Jaume and Sykes, 1992; Harris and Simpson, 1992). Aftershocks of the Landers 


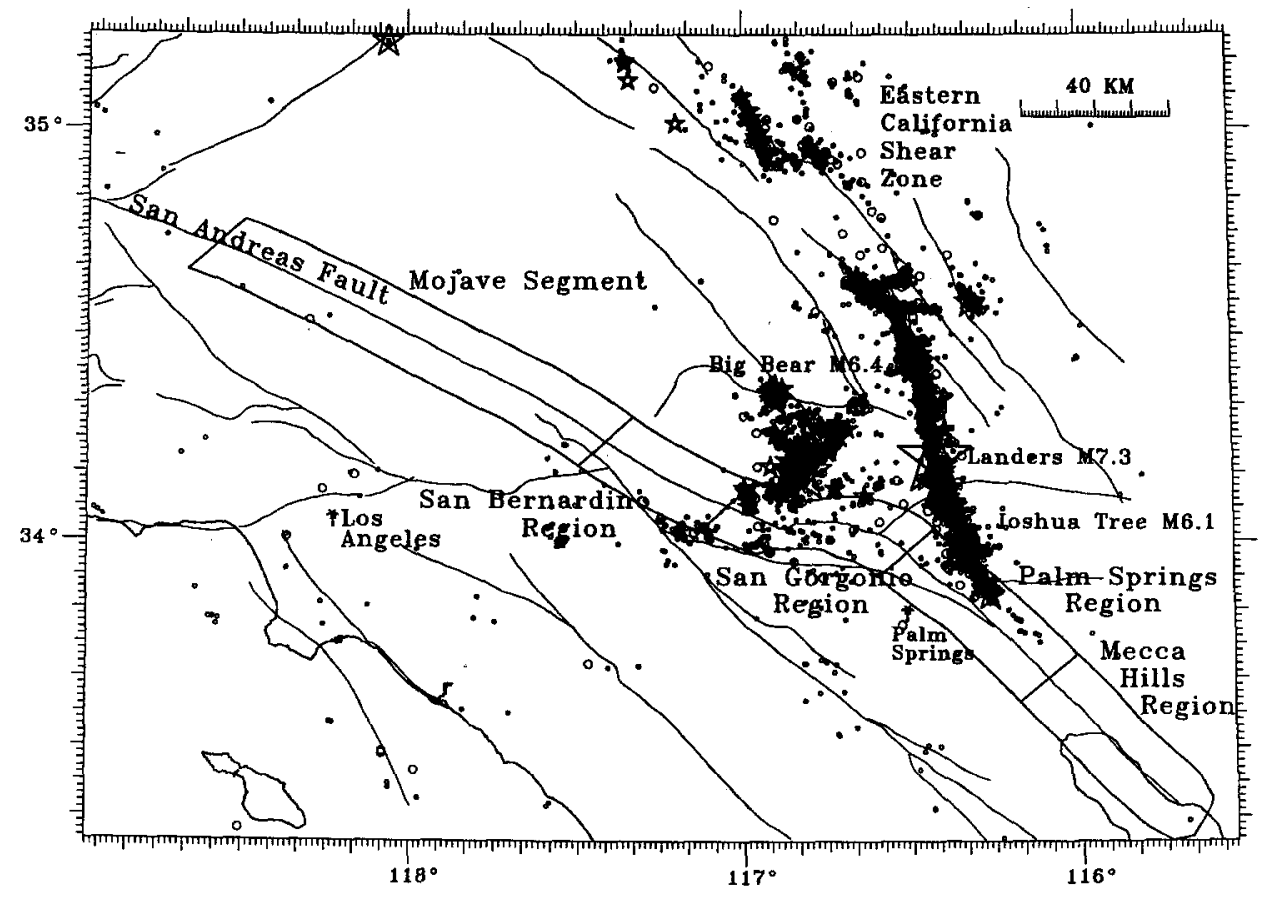

Figure 1. A map of the southern San Andreas showing earthquakes recorded by the Southern California Seismic Network between 28 June and 31 December 1992. Also shown are the five microseismic regions of the southern San Andreas fault defined by Agnew and Jones (1991).

earthquake extended through the Joshua Tree aftershock zone to within a few kilometers of the San Andreas fault (Hauksson et al., 1993) (Fig. 1). The question arose of how to respond to earthquakes occurring near the southern San Andreas fault. Could Landers aftershocks be San Andreas foreshocks? Concern about the possibility of a major San Andreas earthquake was so high that the California Earthquake Prediction Evaluation Council (CEPEC) recommended that the state of California prepare for an imminent earthquake alert if an $M \geqq 6$ earthquake were to occur "on or near" the southern San Andreas fault.

The probability of such an $M 6$ earthquake being a San Andreas foreshock was not formally estimated by CEPEC. It was clear that the Agnew and Jones (1991) results did not apply, because the seismicity of the region had changed with the addition of Landers aftershocks. Because of the increased hazard on the southern San Andreas fault associated with the stress changes, CEPEC took action without a formal statistical analysis. However, this situation could arise again, and a formal treatment of the problem might be helpful in such a situation. The unverifiable assumptions that must be made to complete the analysis prevent it from providing an absolute result but do provide a basis for a comparative assessment of hazard.

This study presents a modification of Agnew and Jones's results to determine the probability that an earthquake that occurs near a major fault during an aftershock sequence will be a foreshock to a characteristic mainshock on that fault, hereafter called the characteristic foreshock probability. We find that the much higher rate of aftershocks compared to the previous background seismicity serves to lower the characteristic foreshock probability immediately after the mainshock, but as the rate of aftershocks decreases with time, the characteristic foreshock probability will increase. However, the increase in the background probability of a San Andreas mainshock (the probability at any moment in the absence of a potential foreshock) caused by the Landers earthquake also increases the characteristic foreshock probability, in part compensating for the decrease caused by the aftershocks.

\section{Derivation}

\section{Original Formulation}

Agnew and Jones (1991) assumed that foreshocks and mainshocks are theoretically separable from background seismicity occurring near the fault. Then, an earthquake near the fault is either a background event or a foreshock, although we do not know which until after the fact. As an example of their approach, suppose that characteristic mainshocks occur on a fault on average every $500 \mathrm{yr}$. If half of them have foreshocks (defined as being within 3 days of the mainshock), we then expect a foreshock every $1000 \mathrm{yr}$. If background events 
occur on or near this fault on average every $10 \mathrm{yr}$, then we will record 100 background earthquakes in the same time as one foreshock. Thus, when an earthquake happens that is either a background earthquake or a foreshock (and we cannot tell which), it has about one chance in 100 of being a foreshock. This makes the probability of a mainshock in the next 3 days $1 \%$. While this is low, it is almost 600 times the background 3-day probability, which is (assuming a Poissonian process) 3 in 500 times 365 , or $0.00165 \%$.

This example computes the probability that a mainshock will soon occur, given a foreshock or background earthquake; that is, a conditional probability. It depends on three quantities: the rate of background seismicity, the probability of the mainshock, and the rate at which foreshocks precede the mainshocks. In formal terms, Agnew and Jones (1991) define probabilistic events as follows:

$B$ : a background event occurs,

$F$ : a foreshock occurs, and

$C$ : a characteristic mainshock will occur.

They calculate $P(C \mid F \cup B)$, the probability of a mainshock after a foreshock or background event has occurred, called the characteristic foreshock probability, to be

$$
P(C \mid F \cup B)=\frac{P(F \mid C) P(C)}{P(F \mid C) P(C)+P(B)} .
$$

Thus, as in the example, the characteristic foreshock probability depends on the long-term probability of the mainshock, $P(C)$, the rate of background seismicity, $P(B)$, and the rate at which foreshocks precede mainshocks, $P(F \mid C)$.

Agnew and Jones (1991) also expanded the formulation into four dimensions (two spatial dimensions, time and magnitude). Using data from foreshocks to strikeslip earthquakes in California, they assumed that foreshocks occur within $10 \mathrm{~km}$ and 3 days of their mainshock and that all magnitudes of foreshocks are equally likely. Incorporating these assumptions into $P(F \mid C)$, the rate at which foreshocks precede mainshocks, they showed that the characteristic foreshock probability is

$$
P(C \mid F \cup B)=\frac{N_{m} P(C) / A_{c} \delta_{1}}{\left(N_{m} P(C) / A_{c} \delta_{1}\right)+\Lambda_{s}\left(\chi_{0}\right) e^{-\beta M}},
$$

where $N_{m}$ is the percentage of foreshocks within one unit of magnitude difference with the mainshock (i.e., the percentage of $M 7$ mainshocks with an $M 6$ to 7 foreshock or with an $M 5$ to 6 foreshock), assumed from data from California to be $0.15, A_{c}$ is the length of the fault segment, $\delta_{1}$ is the time interval, assumed to be 3 days, and $\Lambda_{s}\left(x_{0}\right) e^{-\beta M}$ is the rate density per unit fault length $\left(x_{0}\right)$ of background seismicity on that fault segment.

\section{New Modification}

One of the critical assumptions of the Agnew and Jones (1991) method is that the rate density of background seismicity determined from the earthquake catalog represents the rate density of all nonforeshocks near the fault. An aftershock sequence in a region clearly violates that assumption. In this case, we want to calculate the probability that a characteristic mainshock will occur, given that an earthquake has occurred that is either a foreshock, a background event, or an aftershock to a previous event, $P(C \mid F \cup B \cup A)$, where $A$ is the probabilistic event of the occurrence of an aftershock to a previous event. The derivation of equation (1) depends upon the assumed relationship between the different events. Agnew and Jones (1991) assumed that $F$ and $B$ were disjoint (an event could be one or the other but not both) because, even if they were theoretically independent, if a mainshock were to occur right after a background earthquake, we would call it a foreshock. In this modification, foreshocks $(F)$ and background events $(B)$ are still assumed to be disjoint; however, background events $(B)$ and aftershocks $(A)$ are assumed to be independent (i.e., the occurrence of aftershocks does not change the rate of background events). Following the derivation in Agnew and Jones, (1) becomes

$$
\begin{aligned}
& P(C \mid F \cup B \cup A) \\
& =\frac{P(F \mid C) P(C)}{P(F \mid C) P(C)+P(B)+P(A)-P(F \cap A)-P(B \cap A)},
\end{aligned}
$$

where $P(A)$ is the probability of aftershocks to the previous mainshock. However, since $B$ and $A$ are independent, $P(B \cap A)=P(B) * P(A)$.

Unlike the relationship between foreshock and background events, a foreshock to one event could quite plausibly be an aftershock to another. The value of $P(F$ $\cap A$ ) depends on the relationship between foreshocks and aftershocks. One assumption is that they are independent-i.e., the occurrence of the aftershocks does not increase the probability that a foreshock will precede the next mainshock [an increase in the probability of a characteristic mainshock irrespective of the occurrence of a potential foreshock, even if it was caused by the aftershock's mainshock, is contained in $P(C)$ ]. At the other extreme, one could assume that foreshocks are a subset of the aftershocks-i.e., that the characteristic mainshock has foreshocks only when aftershocks to another earthquake are happening near the fault. We think the assumption of independence is more suitable - aftershocks could also be foreshocks but do not change the 
physics of the seismogenic process. In this case, (3) can be expressed as

$P(C \mid F \cup B \cup A)$

$$
=\frac{P(F \mid C) P(C)}{P(F \mid C) P(C)+P(B)+P(A)-P(F \mid C) P(C) P(A)-P(B) P(A)} .
$$

Because $P(B), P(A)$, and $P(F \mid C) P(C)$ are all small numbers, this can be approximated by

$$
P(C \mid F \cup B \cup A) \cong \frac{P(F \mid C) P(C)}{P(F \mid C) P(C)+P(B)+P(A)} .
$$

If we assumed foreshocks were a subset of aftershocks, then the probability of the intersection, $P(F \cap$ $A$ ), would be the probability of foreshocks or $P(F)$, so (4) would become

$$
P(C \mid F \cup B \cup A)=\frac{P(F \mid C) P(C)}{P(B)+P(A)-P(B) P(A)}
$$

Reasenberg and Jones (1989) showed that the rate of aftershocks, $\lambda$, is a function of magnitude and time from the mainshock and is given by

$$
\lambda(t, M)=10^{[a+b(M m-M)]}(t+c)^{-p},
$$

where $a, b, p$, and $c$ are parameters that can be determined for each aftershock sequence. Using the rate in (5), the multi-dimensional case of Agnew and Jones (1991) can be modified, as was done in (2), so that (3) becomes

$$
P(C \mid F \cup B \cup A)
$$

$$
=\frac{N_{m} P(C) / A_{c} \delta_{1}}{N_{m} P(C) / A_{c} \delta_{1}+\Lambda_{s}\left(x_{0}\right) e^{-\beta M}+\Lambda_{a}(t+c)^{-p} e^{-\beta M}}
$$

where $t$ is time since the mainshock. The rate density of aftershocks, $\Lambda_{a}$, is

$$
\Lambda_{a}=\frac{10^{\left(a+b M_{m}\right)} * b * e}{A_{c}}
$$

Application to the San Andreas Fault

To apply these results to the San Andreas fault after the Landers earthquake, we assume the segmentation of the fault and the rates of background seismicity determined by Agnew and Jones (1991) (Fig. 1). The parameters of the Landers aftershock sequence were very close to the average California values (Sieh et al., 1993), with $a=-1.82, b=0.9, p=1.04$, and $c=0.07$. We assume that the rate of Landers aftershocks near the San
Andreas fault follows the average Landers decay rate and magnitude distribution (i.e., we use the $b, p$, and $c$ values determined for the whole sequence). Seven percent of the aftershocks occurred within $10 \mathrm{~km}$ of the San Andreas fault (Agnew and Jones's criterion for potential foreshocks) near Palm Springs and $0.6 \%$ occurred within $10 \mathrm{~km}$ of the San Andreas fault near San Bernardino. Thus, the $a$ values for aftershocks in the Palm Springs and San Bernardino regions are -2.92 and -4 , respectively $[-1.82-\log (0.07)$ and $-1.82-\log (0.006)]$.

If we assume that $P(C)$, the probability of the mainshock without a potential foreshock for the Coachella Valley segment, is a constant $1.3 \%$ /yr as estimated by the Working Group on California Earthquake Probabilities (WGCEP, 1988) [we use this here to be compatible with Agnew and Jones (1991)], we obtain an unusual, counter-intuitive result. Because the probability of an $M 6$ aftershock near the San Andreas fault was so high immediately after the Landers earthquake (on 28 June the 72 -hr probability of an $M \geqq 6$ aftershock in the Palm Springs region of the San Andreas fault was almost $2 \%$ ), the calculated characteristic foreshock probability $[P(C \mid F \cup B \cup A)]$ is very low- $0.02 \%$ for an $M 6$ event (Fig. 2). As the aftershocks decay with time after the Landers mainshock, the characteristic foreshock probability increases. Applying (6), the characteristic foreshock probability that an $M 6$ in Palm Springs will be followed by an $M 7.5$ mainshock rises from $0.02 \%$ immediately after the Landers earthquake to $5 \% 1 \mathrm{yr}$ later (Fig. 2). By comparison, the characteristic foreshock probability for an $M 6$ event in this region before the Landers earthquake occurred was $21 \%$.

Most seismologists agree that an $M 6$ earthquake on the San Andreas fault immediately after the Landers earthquake would not have been an inconsequential event. This apparent contradiction lies in the use of a constant $P(C)$. The characteristic foreshock probability is highly dependent on $P(C)$ (Fig. 3). Although Agnew and Jones (1991) used the long-term probability from WGCEP (1988) for $P(C), P(C)$ is not the long-term probability of the characteristic mainshock. Rather, $P(C)$ is the probability of the mainshock at this instant, in the absence of a possible foreshock. Seismologists thought the probability of a San Andreas mainshock on 28 June to be relatively high, even though an $M 6$ potential foreshock had not occurred. Several authors have shown that the changes in elastic stresses on the San Andreas fault caused by the Landers earthquake were such as to make an earthquake on the San Andreas fault more likely (Stein et al., 1992; Jaume and Sykes, 1992; Harris and Simpson, 1992). Much of the concern immediately after the Landers earthquake was because of the'possibility that the Landers earthquake would turn out to be a foreshock to a San Andreas mainshock. As time passed without a San Andreas earthquake, the concern abated. These types of temporal changes in the $P(C)$ of a San Andreas earth- 


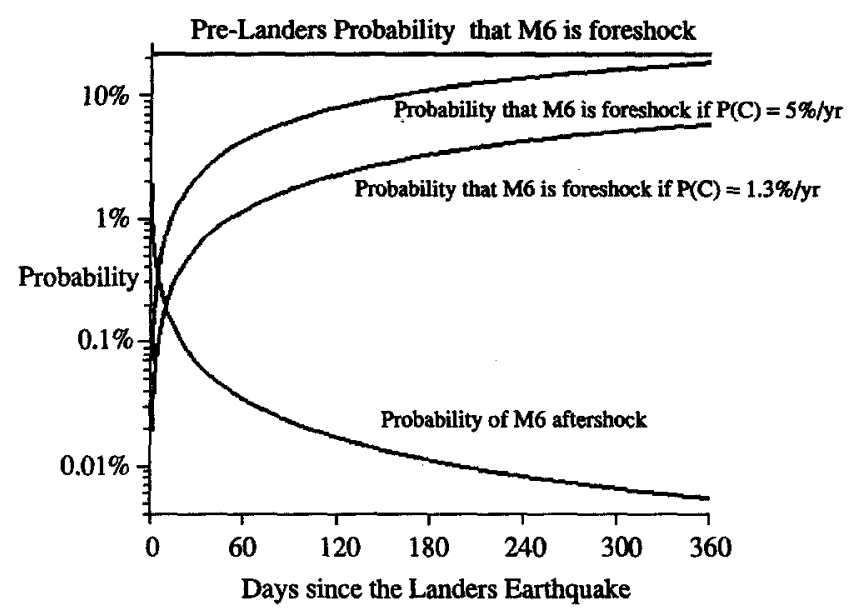

Figure 2. A plot of probability versus time since the Landers earthquake for the probability of an aftershock of $M \geqq 6$ occurring within $10 \mathrm{~km}$ of the San Andreas fault in the Palm Springs region, the characteristic foreshock probability $[P(C \mid F \cup$ $B \cup A$ ), see text] for an $M 6$ event in the Palm Springs region assuming a long-term probability, $P(C)$, of $1.3 \% / \mathrm{yr}$, and the characteristic foreshock probability in the Palm Springs region assuming a long-term probability of $5 \% / \mathrm{yr}$. This does not include the effect of a change in the probability of the San Andreas mainshock, irrespective of the occurrence of possible foreshocks $[P(C)]$, and thus is probably not the best representation of the actual hazard (see text and Fig. 4).

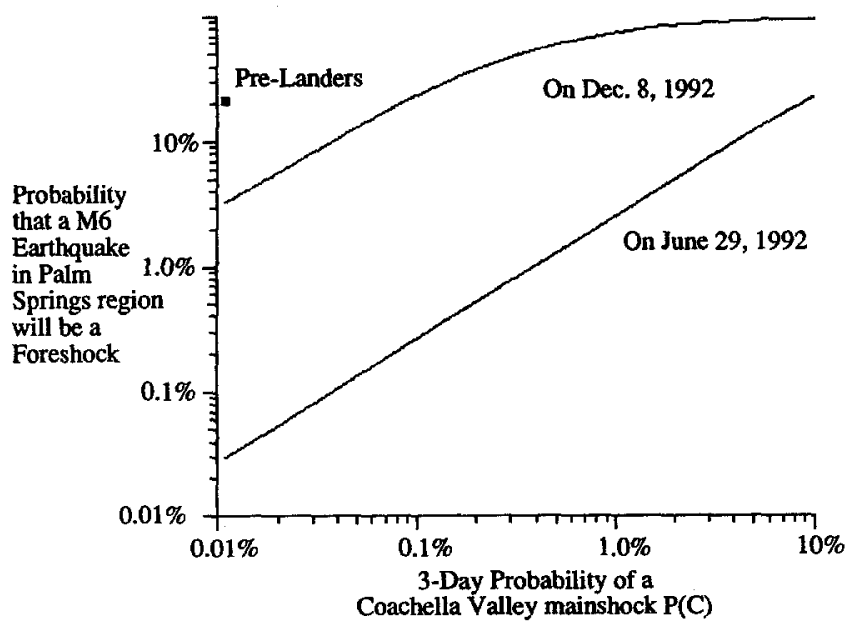

Figure 3. A plot of the characteristic foreshock probability $[P(C \mid F \cup B \cup A)$, see text] versus the assumed long-term probability, $P(C)$, for the Palm Springs region of the southern San An dreas fault on 29 June 1992 ( 1 day after the Landers earthquake) and 28 December 1992 (6 months after the Landers earthquake). quake would significantly alter the temporal behavior of the characteristic foreshock probability.

\section{Time-Variant $\mathrm{P}(\mathrm{C})$}

A more physically reasonable characteristic foreshock probability can be formulated by assuming that $P(C)$ for a San Andreas earthquake is not constant and decays with time from the Landers mainshock. The rate of mainshocks after foreshocks follows a temporal form similar to aftershocks after mainshocks (Jones, 1985; Reasenberg and Jones, 1989). Thus, the probability of a San Andreas mainshock after the Landers earthquake could have the form of $P_{c 0}(t+c)^{-p}$, where $P_{c 0}$ is the probability of the San Andreas mainshock in the first 3 days after Landers, and $c$ and $p$ are the aftershock decay parameters from the Landers aftershock sequence. [This assumes that the probability of a mainshock after a possible foreshock (the Landers earthquake, in this case) is proportional to the rate of aftershocks-i.e., a mainshock after a foreshock is an aftershock that got too big.] Equation (5) would then become

$P(C \mid F \cup B \cup A)$

$=\frac{N_{m} P_{c 0}(t+c)^{-p} / A_{c} \delta_{1}}{N_{m} P_{c 0}(t+c)^{-p} / A_{c} \delta_{1}+\Lambda_{s}\left(x_{0}\right) e^{-\beta M}+\Lambda_{a}(t+c)^{-p} e^{-\beta M}}$.

Reorganizing $A_{c},(t+c)^{p}$, and $\delta_{1}$, this becomes

$P(C \mid F \cup A \cup B)$

$$
=\frac{N_{m} P_{c 0}}{N_{m} P_{c 0}+\Lambda_{s} e^{-\beta M}(t+c)^{p}+\Lambda_{a} e^{-\beta^{\prime} M}}
$$

where

$$
\Lambda_{s}=\frac{10^{a} \beta \delta_{1}}{T} \text { and } \Lambda_{a}=10^{a+b M_{m}} b^{\prime} \delta_{1}
$$

To demonstrate how this would work, Figure 4 shows how the characteristic foreshock probability for an $M 6$ event at Palm Springs would vary when $P(C)$ is a function of time. Before the Landers earthquake $(t \leqq 0), P(C)$ is $1.33 \% / \mathrm{yr}$ from WGCEP (1988), and the characteristic foreshock probability is calculated from Agnew and Jones (1991) as $22 \%$. We then assume that the Landers earthquake had a $5 \%$ probability of being followed by a San Andreas mainshock within 3 days $\left[P_{c 0}\right.$ in (8)], and calculate $P(C \mid F \cup A \cup B)$ from (8). We assume that $P(C)$ does not drop below the long-term level of $1.3 \% / \mathrm{yr}$, so after $P(C)=P_{c o} /(t+c)^{p}$ becomes smaller than the longterm $P(C)$ (which in this case happens around 1 year after the Landers earthquake), $P(C \mid F \cup A \cup B)$ is calculated from (6). 


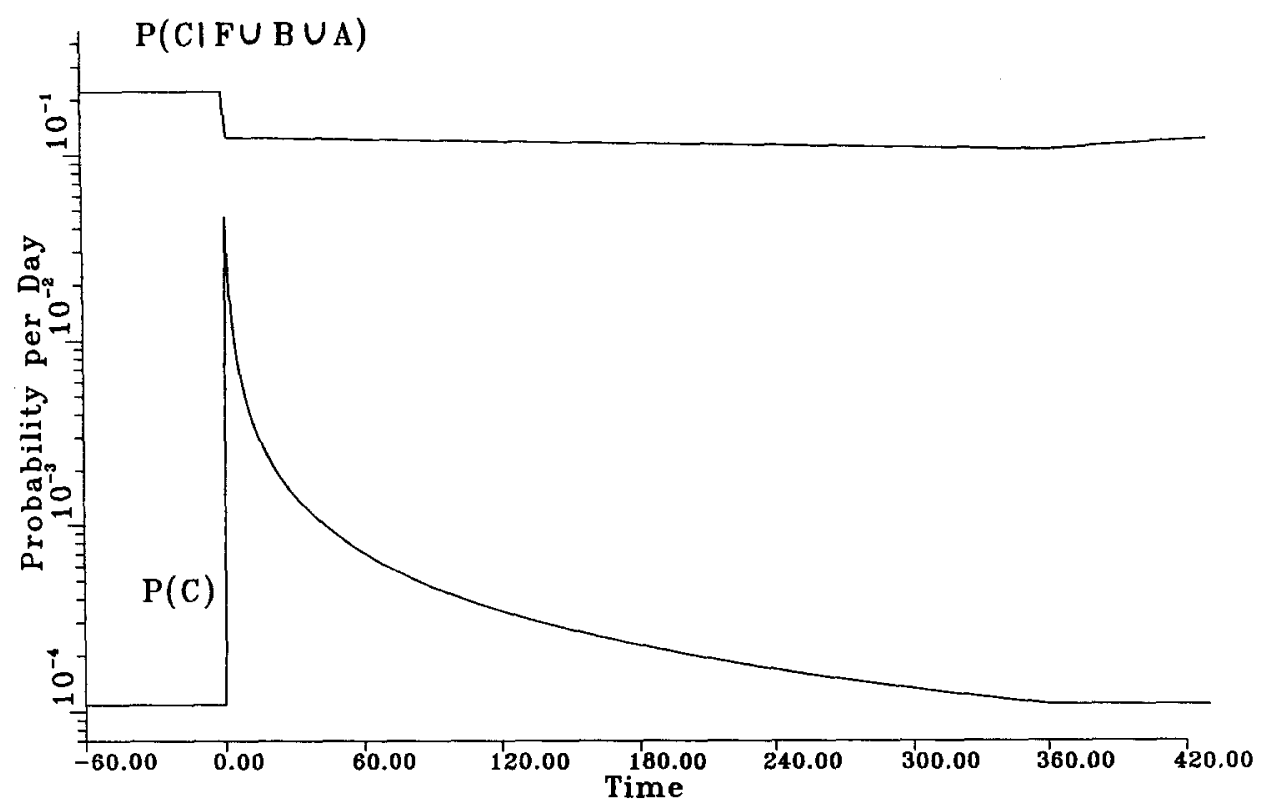

Figure 4. A plot of probability versus time since the Landers earthquake, showing the assumed time-variant $P(C)$ (the probability of the San Andreas mainshock in the absence of a potential foreshock), and the calculated characteristic foreshock probability $[P(C \mid F \cup B \cup A)$, see text] under these assumptions for an $M 6$ event within $10 \mathrm{~km}$ of the Palm Springs region of the San Andreas fault.

\section{Discussion}

An aftershock sequence near the San Andreas fault lowers the probability that an earthquake in that region will be a foreshock to a characteristic mainshock, because nonforeshocks have become more common. However, if the first mainshock has increased the probability of a characteristic San Andreas event irrespective of the occurrence of a potential foreshock, this may compensate for the decrease, minimizing the temporal variation for the segment where the aftershocks are occurring. However, the question arises of how to handle other regions of the same fault segment where the aftershocks are not occurring, such as the Mecca Hills region of the Coachella Valley. If one assumes that the probability of a characteristic earthquake on all of the Coachella Valley segment was 5\% for the 3 days after Landers, and not just in Palm Springs as assumed above, then if an $M 6$ event had occurred in the Mecca Hills region of the Coachella Valley segment (away from the Landers aftershocks), the characteristic foreshock probability would have been $99 \%$. One could argue, however, that because $P(C)$ increases as a result of the possibility that the Landers earthquake is a San Andreas foreshock, and foreshocks have only been recorded within $10 \mathrm{~km}$ of their mainshock, the increase in $P(C)$ occurs only in the Palm Springs region.

One year after the Landers earthquake, the possibility that the Landers earthquake could be a foreshock to a San Andreas mainshock no longer produces daily probabilities of a San Andreas mainshock higher than the long-term probabilities assumed by WGCEP (1988). However, the appropriate value of $P(C)$ for the southern San Andreas fault is subject to much debate. Work in progress by the Southern California Earthquake Center suggest much lower probabilities than those of WGCEP. Unfortunately, as shown above, the assumed value of $P(C)$ strongly affects the resulting foreshock probabilities.

To examine the range of possibilities, I test two end members, both estimated from the rate of southern California earthquakes. Two studies, one of the rate of $M$ $\geqq 7$ earthquakes since 1800 (Savage, 1993) and one of $M \geqq 5$ events since 1932 (Hutton and Jones, 1993), found similar rates of $M \geqq 7$ earthquakes and predict annual probabilities of $M \geqq 7$ earthquakes in southern California of about $4 \%$. Three of the $8 M \geqq 7$ events in southern California have been on the San Andreas system, so one could assume 1.5\% annual probability for the San Andreas. Divided among three segments, this implies $0.5 \%$ annual probability per segment. At the other extreme, the rate of moderate to large earthquakes in southern California increased in 1986, beginning with the 1986 North Palm Springs earthquake. Since then, the rate of $M \geqq 5$ earthquakes (with aftershocks removed) has approximately doubled compared to previous years. Moreover, the $b$ value of the magnitude frequency (the relative number of small to large earthquakes) has decreased (Fig. 5), implying an even greater increase in the rate of large earthquakes. The seismicity rate since 1986 is 


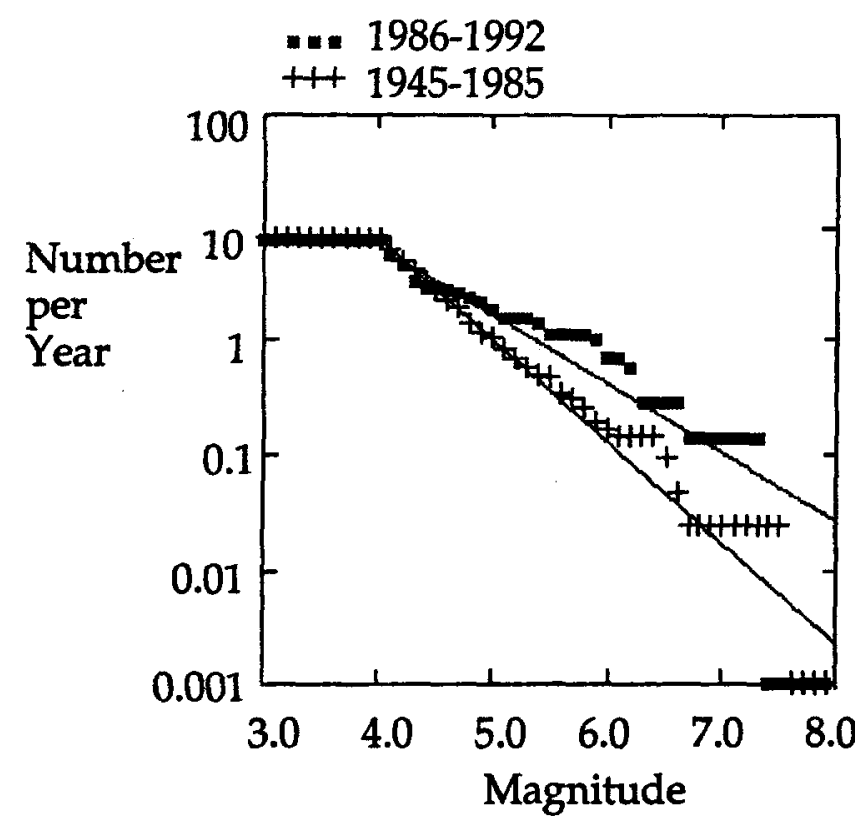

Figure 5. A plot of the cumulative number of earthquakes per year equal to or greater than magnitude $M$ versus $M$ recorded by the Southern California Seismographic Network between $32^{\circ} 30^{\prime} \mathrm{N}$ and $36^{\circ} 0^{\prime} \mathrm{N}$ from 1945 to 1985 (crosses) and from 1986 to 1992 (squares).

$$
N(M)=1.7 \times 10^{3} * 10^{-0.6 M},
$$

where $N$ is the number of earthquakes of magnitude $M$ or larger per year. An extrapolation of this rate to $M \geqq$ 7 events implies a recurrence interval for such large events of $8 \mathrm{yr}$ and an annual probability of an $M \geqq 7$ earthquake of $12 \%$, or three times higher than the 200 -yr average. Thus, two possible probabilities for the southern San Andreas are $0.5 \% / \mathrm{yr}$, and $1.5 \% / \mathrm{yr}$ probability for each segment's $P(C)$.

The characteristic foreshock probabilities for the regions of the southern San Andreas fault are shown in Table 1 , assuming $P(C)=0.5 \% / \mathrm{yr}$ and $1.5 \% / \mathrm{yr}$ for the three segments, to show the range of possibilities. Continuing Landers aftershocks are included for the San Bernardino and Palm Springs regions. At this level, an earthquake near the Mecca Hills and Mojave regions would be significantly more likely to be a foreshock than similar-sized events in the other regions of the southern San Andreas fault.

Given the large number of unverifable assumptions in this analysis, any practical use of the results would be difficult to undertake. The primary use of these results should be to understand the implications of the assumptions in what is sometimes an unintuitive analysis. This can also allow a better understanding of the relative hazards of different sections of the San Andreas fault. It is likely that in the future, other aftershock zones will approach the San Andreas fault. The Calaveras, Gar-
Table 1

Characteristic Foreshock Probabilities: Probability that an M 6 Earthquake within $10 \mathrm{~km}$ of the San Andreas Fault Will Be Followed by a Characteristic Earthquake ( $M \geqq 7.5$ ) within 3 Days

\begin{tabular}{|c|c|c|c|c|c|}
\hline \multirow[b]{3}{*}{ Assumptions } & \multicolumn{5}{|c|}{ Regions } \\
\hline & \multirow[b]{2}{*}{ Mojave } & \multicolumn{2}{|c|}{$\begin{array}{c}\text { San Bernardino } \\
\text { Mountains }\end{array}$} & \multicolumn{2}{|c|}{ Coachella Valley } \\
\hline & & $\begin{array}{c}\text { San } \\
\text { Bernardino }\end{array}$ & $\underset{\text { Sangonio }}{\text { Gorgan }}$ & $\begin{array}{l}\text { Palm } \\
\text { Springs }\end{array}$ & $\begin{array}{c}\text { Mecca } \\
\text { Hills }\end{array}$ \\
\hline $\begin{array}{l}\text { Pre-Landers } \\
\text { WGCEP }(1988) P(C)\end{array}$ & 0.21 & 0.07 & 0.04 & 0.22 & 0.36 \\
\hline $\begin{array}{l}1 \text { July } 1993 \\
P(C)^{*} \mathrm{SBM}, \mathrm{CV}, \\
\text { and } \mathrm{M}=1.5 \% / \mathrm{yr} \\
P(C)^{*} \mathrm{SBM}, \mathrm{CV} \\
\text { and } \mathrm{M}=0.5 \% / \mathrm{yr}\end{array}$ & 0.29 & 0.10 & 0.09 & 0.06 & 0.39 \\
\hline
\end{tabular}

${ }^{*} P(C)$ is the probability that a characteristic earthquake will occur without the potential foreshock on a given fault segment. SBM is the San Bernardino Mountain segment, $\mathrm{CV}$ is the Coachella Valley segment, and $M$ is the Mojave segment.

lock, Big Pine, Pinto Mountain, Cucamonga, and San Jacinto faults are all major, active faults that intersect the San Andreas fault. Although we know that aftershocks are normal, the psychological response to continued shaking can affect our evaluation of the hazard. The analysis provides a mechanism to remind us that aftershocks are a normal part of the earthquake process and not in themselves a sign of future tragedy.

\section{Conclusions}

The occurrence of an aftershock sequence near a major fault in general decreases the probability that an earthquake near that fault will be a foreshock to a characteristic earthquake on the fault, because it increases the rate of nonforeshock activity. This result must be qualified, however, by the effect of the original mainshock on the major fault. If the first earthquake increases the chances of the characteristic earthquake, this will, in turn, increase the foreshock probability, in part off-setting the decrease caused by the aftershocks. In application to the southern San Andreas fault, the occurrence of aftershocks to the 1992 Landers earthquake near Palm Springs has changed the relative hazard associated with possible foreshocks in different regions, so that an earthquake in the Mecca Hills would be significantly more ominous than an earthquake near Palm Springs.

\section{Acknowledgments}

I would like to thank Andy Michael, Egill Hauksson, Jim Savage, and especially Tom Heaton for careful and thoughtful reviews of this article. 


\section{References}

Agnew, D. C. and L. M. Jones (1991). Prediction probabilities from foreshocks, J. Geophys. Res. 96, 11959-11971.

Harris, R. A. and R. W. Simpson (1992). Changes in static stress on southern California faults after the 1992 Landers earthquake, $\mathrm{Na}$ ture 360, 251-254.

Hauksson, E., L. M. Jones, L. K. Hutton, and D. Eberhart-Phillips (1993). The 1992 Landers earthquake sequence: seismological observations, J. Geophys. Res. 98, 19538-19858.

Hutton, L. K. and L. M. Jones (1993). Local magnitudes and apparent variations in seismicity rates in southern California, $B u l l$. Seism. Soc. Am. 83, 313-329.

Jaume, S. and L. R. Sykes (1992). Changes in the state of stress on the southern San Andreas fault resulting from the California earthquake sequence of April to June 1992, Science 258, 13251328.

Jones, L. M. (1985). Foreshocks and time-dependent earthquake hazard assessment in southern California, Bull. Seism. Soc. Am. 75, 1669-1680.

Jones, L. M., K. E. Sieh, D. C. Agnew, C. R. Allen, R. Bilham, M. Ghilarducci, B. Hager, E. Hauksson, K. Hudnut, D. Jackson, and A. Sylvester (1991). Short-term earthquake hazard as- sessment for the southern San Andreas fault, U.S. Geol. Surv. Open-File Rept. 91-32, 70 pp.

Reasenberg, P. A. and L. M. Jones (1989). Earthquake hazard after a mainshock in California, Science 243, 1173-1176.

Savage, James C. (1993). Probability of one or more $M \geqq 7$ earthquakes in southern California in 30 years, Geophys. Res. Lett. 20, 2111-2114.

Sieh, K., L. M. Jones, E. Hauksson, K. Hudnut, D. Eberhart-Phillips, T. Heaton, S. Hough, K. Hutton, H. Kanamori, A. Lilje, S. Lindvall, S. McGill, J. Mori, C. Rubin, J. Spotila, J. Stock, H. Thio, J. Trieman, B. Werniche, and J. Zachariasen (1993). Near-field investigations of the Landers earthquake sequence, April-July, 1992, Science 260, 171-175.

Stein, R., G. C. P. King, and J. Lin (1992). Change in failure stress on the southern San Andreas fault system caused by the 1992 magnitude $=7.4$ Landers earthquake, Science 258, 1328-1332.

Working Group on California Earthquake Probabilities (1988). Probabilities of large earthquakes occurring in California on the San Andreas fault, U.S. Geol. Surv. Open-File Rept. 88-398, 62 pp.

U.S. Geological Survey

Pasadena, California 91106

Manuscript received 2 August 1993. 